\title{
Jar-by-Jar: Curation Improvements to the Herpetology Collection at CUMNH
}

\author{
Emily Braker ¥ \\ ‡ Vertebrate Collections Manager, University of Colorado Museum of Natural History, Boulder, United States of America
}

Corresponding author: Emily Braker (emily.braker@colorado.edu)

Received: 15 Apr 2018 | Published: 04 Jul 2018

Citation: Braker E (2018) Jar-by-Jar: Curation Improvements to the Herpetology Collection at CUMNH.

Biodiversity Information Science and Standards 2: e25853. https://doi.org/10.3897/biss.2.25853

\begin{abstract}
The University of Colorado Museum of Natural History (CUMNH) Herpetology Collection is comprised of over 65,000 fluid-preserved specimens representing over 2,500 taxa from more than 70 countries. Despite its active use, a history of irregular topping up schedules and a decades-long dearth in rehousing projects due to budgetary constraints left the collection in substandard conditions. A 2015 survey of roughly $10 \%$ of the collection revealed average ethanol concentrations far below desired levels, with only $15 \%$ of specimen jars surveyed containing optimal preservative strengths of $70 \%$ (+/- $2.5 \%)$. In Fall 2017, CUMNH secured an Institute of Museum and Library Services (IMLS) grant to holistically address shortcomings in the micro- and macro-storage environments within the Herpetology Collection. Program activities include jar-by-jar ethanol remediation using a digital density meter and a topping up algorithm proposed by Notton 2010, collection-wide replacement of faulty jars and lids, and installation of new static and mobile compactor shelving. Updates to nomenclature and a full specimen inventory including condition and location tracking in Arctos also fall within the project scope. This talk will cover progress thus far, our approaches to moving a collection in place, and systematic remedial topping up as a valuable counterpart to routine monitoring in fluid collections.
\end{abstract}




\section{Keywords}

Herpetology, Fluid Collections, Curation, Topping Up, IMLS

\section{Presenting author}

\section{Emily Braker}

\section{References}

- Notton DG (2010) Maintaining concentration: A new practical method for profiling and topping up alcohol preserved collections. Collection Forum 24 (1): 1-27. [In English]. 